\title{
FAILURE OF HIGH UTERINE CONCENTRATIONS OF PROGESTERONE TO INHIBIT MYOMETRIAL ACTIVITY IN VIVO IN THE POST-PARTUM RAT
}

\author{
D. G. PORTER* AND J. R. G. CHALLIS \\ Departments of Anatomy and Obstetrics and Gynecology, \\ Laboratory of Human Reproduction and Reproductive Biology, Harvard Medical School, \\ Boston, Massachusetts, U.S.A.
}

\section{(Received 22nd Fanuary 1974)}

In a pilot experiment to test the feasibility of studying the progesterone 'block' in a species other than the rabbit, it was found that the myometrial activity of the post-partum rat recorded in vivo by means of small indwelling recording balloons was not reduced following intramuscular injections of progesterone (10 $\mathrm{mg}$ in oil). In view of the ample evidence that progesterone is essential in maintaining pregnancy in the rat after ovariectomy (Johnson \& Challans, 1930; Rothchild \& Meyer, 1940), this paradoxical finding was investigated in more detail.

On the day following parturition, six Holtzman rats were anaesthetized with tribromoethanol intraperitoneally and a small latex recording balloon attached to a polyethylene catheter $(0.015$ in.i.d. $\times 0.043$ in. o.d.) was placed in one uterine horn through a mid-line incision made with antisepsis precautions. The ovaries were removed and the catheter was passed subcutaneously to a point at the back of the neck where it was brought to the exterior. On the day of surgery, the animals were injected subcutaneously with $5 \mu \mathrm{g}$ oestradiol-17 $\beta$. Three further injections of $0.5 \mu \mathrm{g}$ were given daily, beginning 3 to 7 days later. On the last day, the animals received in addition a subcutaneous injection of $25 \mathrm{mg}$ progesterone (crystalline suspension, Upjohn) over the spine (to prevent contamination of the uterus when it was removed subsequently). Intrauterine pressure was monitored continuously from the virtually unrestrained conscious rats by means of Statham pressure transducers and a Grass 7B polygraph. The animals were killed $24 \mathrm{hr}$ after the progesterone treatment. Blood samples were taken from the carotid artery into heparinized tubes, centrifuged immediately at $4^{\circ} \mathrm{C}$ and the plasma was stored at $-20^{\circ} \mathrm{C}$ until analysis. Portions of uterine tissue were removed and frozen immediately. Progesterone was measured in samples of plasma and uterine tissue by radioimmunoassay. The methods used have been described and validated elsewhere (Challis, Davies \& Ryan, 1973).

Spontaneous myometrial activity was not diminished in any of the six rats during the $24 \mathrm{hr}$ after the progesterone treatment (Text-figs 1 and 2). Although the maximum amplitude during this period remained at around $34 \mathrm{mmHg}$,

* Present address: Anatomy Department, Medical School, University Walk, Bristol BS8 ITD. 
the frequency of intrauterine pressure cycles increased significantly $(P<0.005)$. Visual examination of the pressure recordings did not indicate any significant change in the rate of rise of the pressure cycles. Thus, an increase in total uterine activity occurred even though the mean \pm S.E.M. value for the uterine progesterone concentration in the balloon-containing horn at the end of the

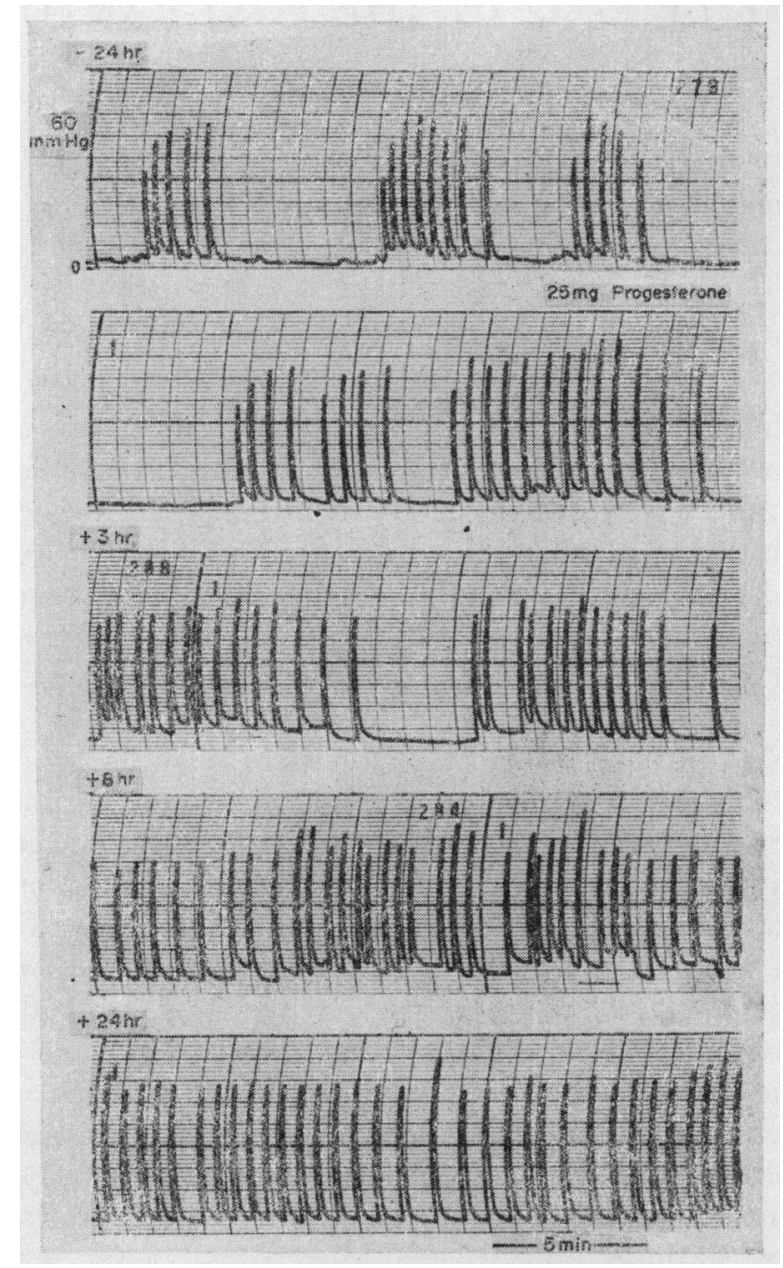

TexT-FIg. 1. Intrauterine pressure recordings from a post-partum rat pretreated with oestradiol-17 $\beta$ ( $5 \mu \mathrm{g} /$ day for 4 days) and receiving $25 \mathrm{mg}$ progesterone as shown. Recordings taken at $-24,0,+8$ and +24 hr. Note the lack of inhibition of uterine activity.

recording period was $354 \pm 73 \mathrm{ng} / \mathrm{g}$ ( $265 \pm 74$ for the intact horn) and the mean plasma progesterone concentration was $102 \pm 9 \mathrm{ng} / \mathrm{ml}$ (Table 1 ). These values exceed the highest concentrations reported during pregnancy in the rat (Csapo $\&$ Wiest, 1969) and the ratio of uterine : plasma progesterone concentration is higher. These results are in contrast to those found in the rabbit since marked falls in both amplitude and rate of rise of pressure cycles are characteristic of the effect of progesterone on the gravid and non-gravid uterus in that species (Csapo \& Takeda, 1965; Porter, 1968). 
It seemed possible that the latent period of progesterone effect might be much longer in the rat than the 8 to $12 \mathrm{hr}$ observed in rabbits (Csapo \& LloydJacob, 1961) and accordingly two further rats were studied in which the ovaries were left in situ and treatment with progesterone was continued for 4 days

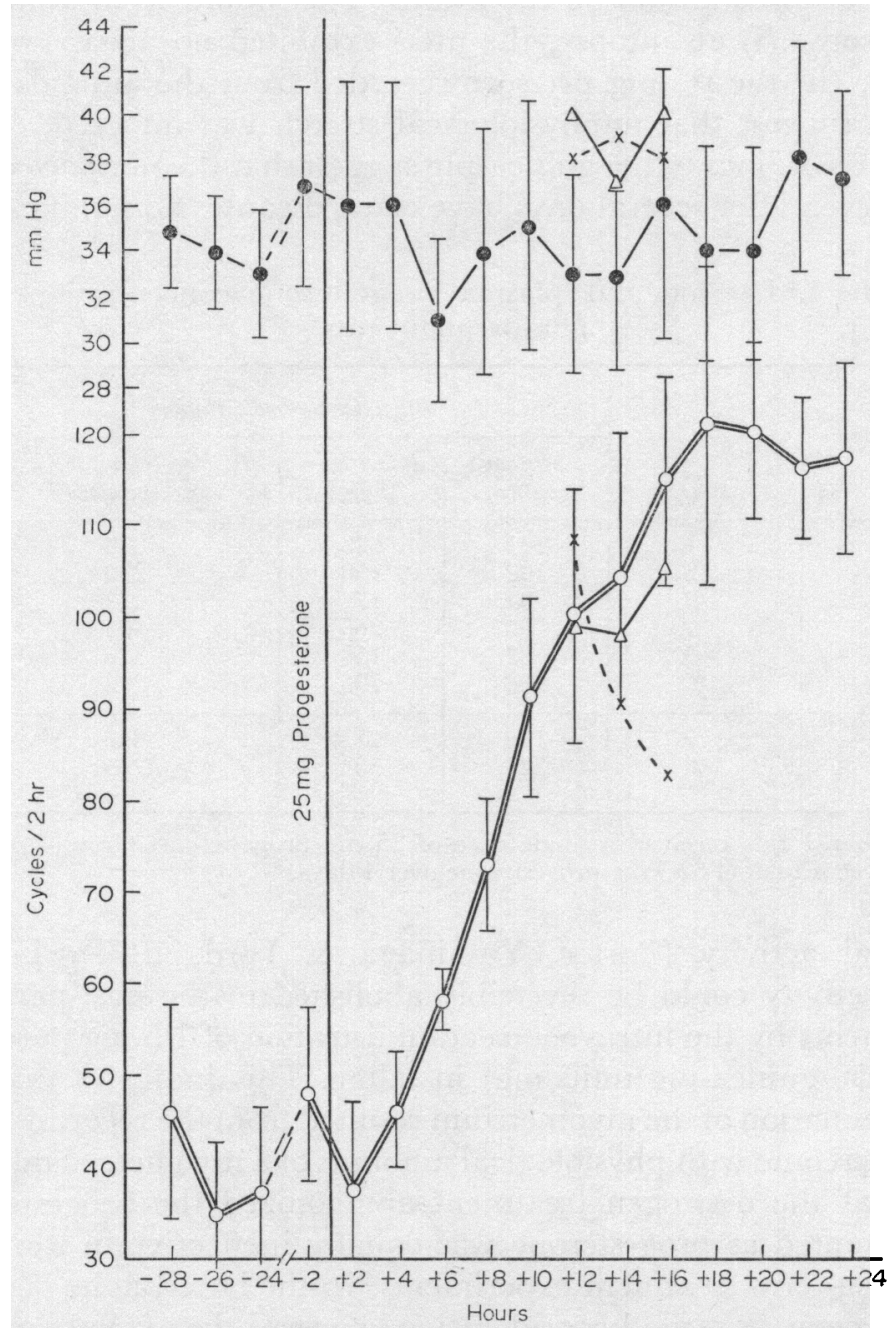

TEXT-FIG. 2. Graph showing mean maximum amplitude (๑) \pm S.E.M. (vertical bars) and mean frequency $(0)$ of intrauterine pressure cycles of post-partum rats at intervals before and after the administration of $25 \mathrm{mg}$ progesterone $(\mathrm{n}=6)$. The mean maximum amplitude and mean frequency of intrauterine pressure cycles in two rats following 4 days of progesterone treatment (total dose $62.5 \mathrm{mg}$ ) are also shown $(\Delta-\Delta$ and $x---x$ ). (The amplitude values indicated by $\Delta$ are $10 \mathrm{mmHg}$ less than actually recorded in order to simplify the graph.)

(25 mg subcutaneously on Day 1; 12.5 mg on Days 2, 3 and 4). Intrauterine pressure was monitored on Day 5 . As can be seen from Text-fig. 2, both the frequency and maximum amplitude were comparable to those of the rats given single injections. At the end of the recording period, the uterine progesterone concentrations were 346 and $260 \mathrm{ng} / \mathrm{g}$ in the two animals respectively (Table 1). 
These data suggest that in the rat, as in the guinea-pig (Porter, 1970), progesterone may not be a myometrial-inhibiting factor, but several potential objections to the present experiments should be considered before such a conclusion is reached. The technique employed to record uterine activity might impose an unphysiological condition on the uterus. This would seem unlikely for the following reasons: (i) at autopsy, the uteri exhibited no macroscopic signs of inflammation, (ii) the resting pressure recorded from the animals $(<7.5 \mathrm{~mm}$ $\mathrm{Hg}$ ) does not suggest that unphysiological stretch was imposed, (iii) electrophysiological recordings in the guinea-pig suggest that the presence of a balloon in the uterus even after several days have elapsed causes no significant artifacts

Table 1. Uterine and plasma progesterone concentrations in non-pregnant rats

\begin{tabular}{c|c|c|c|c}
\hline \multirow{3}{*}{ Group } & \multirow{2}{*}{ Rat no. } & \multicolumn{3}{|c}{ Progesterone concentrations } \\
\cline { 3 - 5 } & & $\begin{array}{c}\text { Plasma } \\
(\mathrm{ng} / \mathrm{ml})\end{array}$ & $\begin{array}{c}\text { Intact horn } \\
(\mathrm{ng} / \mathrm{g})\end{array}$ & $\begin{array}{c}\text { Balloon-containing horn } \\
(\mathrm{ng} / \mathrm{g})\end{array}$ \\
\hline 1 & 1 & 141 & 628 & 688 \\
& 2 & 109 & 168 & 230 \\
& 3 & 84 & 172 & 227 \\
& 4 & 94 & 265 & 405 \\
& 5 & 82 & 153 & 326 \\
\hline 2 & 6 & 104 & 205 & 248 \\
\hline & 7 & 176 & 272 & 346 \\
& 8 & 224 & 303 & 260 \\
\hline
\end{tabular}

Group-1 rats received a single dose of $25 \mathrm{mg}$ progesterone. Group-2 rats received a total of $62.5 \mathrm{mg}$ progesterone over 4 days.

in myometrial activity (Porter, Yoshinaga \& Ford, 1974). Furthermore, myometrial activity could be reversibly abolished in the post-partum rats in these experiments by the intravenous administration of $1.5 \mathrm{mg}$ porcine relaxin (assayed at 150 guinea-pig units/mg) in saline. This indicates that whatever abnormal stimulation of the myometrium resulted from the recording technique it could be overcome with physiological amounts of a myometrial inhibitor. The possibility that the oestrogen treatment antagonized the progesterone effect may be discounted as progesterone was equally ineffective in the pilot study and in the long-term treatment experiments. In the latter, none of the animals received oestrogen. A second consideration concerns the availability of uterine progesterone receptors in the present experiments. Davies \& Ryan (1972) reported low concentrations of receptor protein from Day 15 until term, i.e. at a time when progesterone treatment is effective in prolonging pregnancy, followed by a rise in concentration after parturition. The implications are uncertain but the ratio of uterine: plasma progesterone concentration in the present experiments was higher than reported for intact rats at mid-pregnancy, (Csapo \& Wiest, 1969) which suggests that uptake of the steroid by the uterus was not impaired.

A further possibility is that the uterine muscle of the rat is sensitive to progesterone during pregnancy but becomes refractory following parturition. There 
is no evidence of such a change in sensitivity in any other species, but the possibility is being investigated.

That progesterone does not inhibit myometrial activity in the rat has been reported before by Melton \& Saldivar (1966), who found that the administration in vivo of $12.5 \mathrm{mg}$ progesterone daily for 5 days altered neither the spontaneous electrical activity in vitro recorded by extracellular electrodes nor the conduction velocity of rat myometrium. The present study confirms this work in vivo and provides data on the uterine progesterone concentrations achieved with a similar dose regimen. On the other hand, the in-vitro intracellular electrode studies of Marshall (1959) and Marshall \& Csapo (1961) support the view that progesterone does inhibit the rat myometrium, although a similar study by Casteels \& Kuriyama (1965) showed that the excitability, the spike amplitude and the number of spikes in a train was increased during pregnancy. This finding is difficult to reconcile with an inhibitory action of progesterone. It also may be significant that the negative staircase phenomenon observed in uterine muscle from pregnant rabbits and shown to be due to progesterone cannot be demonstrated in the pregnant rat (Al-Mallah, 1970).

The present experiments raise the question of how progesterone prevents abortion following ovariectomy in the rat. There seem to be two probable mechanisms: (a) an action inhibiting the release of oxytocic substances, e.g. neurohypophysial hormones from mother or fetus; and (b) a key rôle in maintaining the viability of the conceptus which in turn inhibits myometrial activity through an unknown mechanism.

We thank Miss Gail Breed for technical assistance. The work was supported by the following grants: HD 5979-02 from the National Institute of Child Health \& Human Development, 710-0036 from the Ford Foundation and R-226-72 and a post-doctoral fellowship to J.R.G.C., both from the United Cerebal Palsy Fund. Dr D. Fawcett and Dr K. Ryan made helpful comments on the manuscript.

The porcine relaxin powder was kindly provided by the Warner-Lambert Research Institute, Morris Plains, New Jersey, U.S.A.

\section{REFERENCES}

AL-MALLAH, A. K. R. (1970) Functional and structural changes in the myometrium of rats and rabbits under different hormonal conditions. Ph.D. thesis, University of London.

Casteels, R. \& Kurryama, H. (1965) Membrane potential and ionic content in pregnant and nonpregnant rat myometrium. F. Physiol., Lond. 177, 263.

Challis, J. R. G., Davies, I. J. \& Ryan, K. J. (1973) The relationship between progesterone and prostaglandin F concentrations in the plasma of pregnant rabbits. Endocrinology, 93, 971.

Csapo, A. I. \& LloYd-JACOB, M. (1961) Effect of progesterone on pregnancy. Nature, Lond. 192, 329.

CSAPO, A. I. \& TAKEDA, H. (1965) Effect of progesterone on the electric activity and intra-uterine pressure of pregnant and parturient rabbits. Am. J. Obstet. Gynec. 91, 221.

CsAPo, A. I. \& WIEst, W. G. (1969) An examination of the quantitative relationship between progesterone and maintenance of pregnancy. Endocrinology, 85, 735.

Davies, I. \& RyAN, K. J. (1972) The uptake of progesterone by the uterus of the pregnant rat in vivo and its relationship to cytoplasmic progesterone-binding protein. Endocrinology, 90, 507.

Johnson, E. \& Ghallans, J. S. (1930) Ovariectomy and corpus-luteum extract experiments in pregnant rats. Anat. Rec. 47, 300.

Marshall, J. M. (1959) Effects of estrogen and progesterone on single uterine muscle fibers in the rat. Am. J. Physiol. 197, 935. 
Marshall, J. M. \& Csapo, A. I. (1961) Hormonal and ionic influences on the membrane activity of uterine smooth muscle cells. Endocrinology, 68, 1026.

Melton, G. E. \& Saldivar, J. T. (1966) Effect of estrogen and progesterone on impulse conduction in rat myometrium. Am. F. Physiol. 211, 835 .

Porter, D. G. (1968) The local effect of intra-uterine progesterone upon myometrial activity in the rabbit. 7. Reprod. Fert. 15, 437.

Porter, D. G. (1970) The failure of progesterone to affect myometrial activity in the guinea-pig. 7. Endocr. 46, 425.

Porter, D. G., Yoshinaga, K. \& Ford, J. (1974) Progesterone concentration, intraluminal pressure and electrical activity of the guinea pig uterus. $\mathcal{J}$. Endocr. 61, 255.

Rothchild, I. \& MEYER, R. K. (1940) Maintenance of pregnancy in castrated rats by means of progesterone. Proc. Soc. exp. Biol. Med. 44, 402. 